\title{
Bronchial reactions to exposure to welding fumes
}

\author{
Gustavo R Contreras, Moira Chan-Yeung
}

\begin{abstract}
Objective-To study the airway response and its mechanism to welding fumes in six welders with respiratory symptoms.

Methods-Methacholine and welding challenge tests were carried out. The concentration of welding fumes during the exposure test was measured. On two subjects who developed bronchoconstriciton to welding challenge, additional tests were carried out including prick, patch, and inhalation challenges with metal salt solutions.

Results-Three subjects developed immediate bronchial reaction to exposure to welding fume; one to mild steel and stainless steel welding, another to mild steel and galvanised welding, and one only to galvanised welding. They all had a moderate to pronounced degree of non-specific bronchial hyperresponsiveness. The concentration of fumes during welding tests, particularly to galvanised welding, was high. An inhalation challenge test with zinc chloride salt solution in two subjects who reacted to galvanised welding was negative. Prick and patch tests with zinc chloride were also negative.

Conclusions-The airway response to welding in these subjects is non-specific and is due to irritation rather than to sensitisation.
\end{abstract}

(Occup Environ Med 1997;54:836-839)

Keywords: airway response; welding fumes

Occupational asthma has been reported among welders. ${ }^{1-7}$ Most welders who developed asthma were exposed to stainless steel or galvanised metal welding fumes. Asthma related to gas metal arc welding on mild steel has been reported recently ${ }^{7}$ although exposure to manual metal arc welding on mild steel failed to induce asthmas. ${ }^{1}$ Very little is known about the mechanism of asthma induced by welding. It has been suggested that sensitisation to either chromium or nickel is responsible for asthma due to exposure to stainless steel welding fumes whereas sensitisation to zinc is responsible for asthma due to exposure to fumes from galvanised welding. ${ }^{2}{ }^{3}$ Welders have been shown to develop asthma from exposure to contaminants such as welding done on painted surfaces ${ }^{6}$ rather than to metal fumes.

In this report we present the results of welding challenge tests on six subjects who had respiratory symptoms on exposure to welding fumes and the results of immunological tests in two of the subjects who developed bronchoconstriction on exposure to welding fumes.

\section{Subjects and methods}

SUBJECTS

Six welders who attended the University of British Columbia Respiratory Clinic for respiratory symptoms between November 1992 to July 1993 were invited to take part in this study. They were all full time manual arc welders. One welder (subject 6) had worked in pulpmills and was "gassed" on several occasions several years after the onset of respiratory symptoms. The remaining five welders did not give a history of being gassed. Subjects 3,5 , and 6 gave a history compatible with metal fume fever in the past.

This study was approved by our institution's review board for human studies. All subjects gave written informed consent.

SEQUENCE OF TESTING

Visit 1

Interview with skin prick test with common allergens and methacholine challenge test.

Visit 2

Manual arc welding on mild steel as a control test.

Visit 3

Manual arc welding on stainless or galvanised steel. The metal selected for testing was the one that provoked symptoms in the subject tested.

All challenge tests (non-specific and specific) were carried out when the subject's asthma was under control and the diurnal variation in peak expiratory flow was less than $10 \%$. They were performed at least one week apart and at the same time of day. The patients were told not to take bronchodilators for at least six hours before challenge testing. They were allowed to continue using inhaled steroids in the same way as before. For the two subjects who had a positive bronchial reaction to a welding challenge test to galvanised metal, skin prick test, patch test, and a challenge test with the salt of the suspected metal were also carried out.

ALLERGY SKIN TESTS

Allergy skin prick tests were carried out with a battery of 25 common allergens and normal saline and histamine $(1 \mathrm{mg} / \mathrm{ml})$ were used as negative and positive controls respectively. A weal diameter $3 \mathrm{~mm}$ or greater than the negative control 15 minutes after testing was considered to be a positive reaction.

SPIROMETRY

Spirometry was performed, according to the recommendations of the American Thoracic 
Table 1 Characteristics of study subjects

\begin{tabular}{|c|c|c|c|c|c|c|}
\hline & \multicolumn{6}{|l|}{ Subject } \\
\hline & 1 & 2 & 3 & 4 & 5 & 6 \\
\hline Age $(y)$ & 55 & 49 & 39 & 46 & 55 & 58 \\
\hline Ex-smokers & 13 & - & 18 & 2 & 9 & 30 \\
\hline Exposure to welding fumes $(y)$ & 35 & 21 & 20 & 27 & 15 & 38 \\
\hline Duration of symptoms (y) & 10 & 2 & 2 & 8 & 14 & 18 \\
\hline Atopy ${ }^{\star}$ & + & - & + & - & - & - \\
\hline FVC (\% predicted) & 111 & 73 & 110 & 88 & 96 & 74 \\
\hline $\mathrm{FEV}_{1}$ (\% predicted) & 111 & 71 & 92 & 82 & 89 & 65 \\
\hline $\mathrm{PC}_{20}(\mathrm{mg} / \mathrm{ml})$ & $<0.125$ & 3.0 & 4.54 & $>64$ & 0.95 & 0.5 \\
\hline Medications & IS & - & $\beta_{2}+\mathrm{IS}$ & - & $\beta_{2}+\mathrm{IS}$ & $\beta_{2}+\mathrm{IS}$ \\
\hline
\end{tabular}

^Defined as positive reaction to one or more of the common allergens. IS=inhaled steroids; $\beta_{2}=\beta_{2}$ agonists.

Society, ${ }^{8}$ with a computerised volumetric spirometer (Sensor Medics, USA). The results were expressed as a percentage of the predicted values based on the data of Crapo et al. ${ }^{9}$

\section{METHACHOLINE CHALLENGE TEST}

Methacholine challenge test was carried out with a modified tidal breathing method as described by Cockcroft and coworkers. ${ }^{10}$ Briefly, normal saline and doubling concentrations of methacholine, starting at $0.125 \mathrm{mg} / \mathrm{ml}$, were delivered by a Bennett twin nebuliser (output $0.15 \mathrm{ml} / \mathrm{min}$ at an oxygen flow rate of $5 \mathrm{l} / \mathrm{min}$ ) each for a duration of two minutes. The forced expiratory volume in one second $\left(F_{E V}\right)$ was measured at one and three minutes after inhalation of each concentration. The test was stopped when the $\mathrm{FEV}_{1}$ fell by $20 \%$ or more from the lowest value after saline or when the maximal concentration of $64 \mathrm{mg} / \mathrm{ml}$ was used. The provocative concentration of methacholine that induced a $20 \%$ fall in $\mathrm{FEV}_{1}\left(\mathrm{PC}_{20}\right)$ was calculated by the interpolation of the last two concentrations.

WELDING CHALLENGE TEST

Each subject was asked to perform manual arc welding in a room of $13.5 \mathrm{~m}^{3}(1.5 \mathrm{~m}$ wide, $3 \mathrm{~m}$ long, $3 \mathrm{~m}$ high). Electrodes E7018-A1, 3171, and 7018 (Lincoln Electric, Ohio, USA) were used for mild steel, stainless steel, and galvanised welding challenge tests respectively. To reproduce the working conditions of these workers, ventilation was not provided and the fumes left the room passively through a window $(30 \mathrm{~cm} \times 20 \mathrm{~cm})$ near the ceiling. After baseline spirometry measurement, the subject was asked to weld with a manual arc for 15 minutes. Spirometry was repeated at one and five minutes after exposure. If the fall in $\mathrm{FEV}_{1}$ was less than $15 \%$ from the baseline, the subject was asked to continue welding for another 15 minutes. The test was discontinued if the subject complained of any respiratory discomfort. If the subject had no symptoms or fall in FEV , the welding test was continued for a total duration of one hour. After testing, spirometry was performed every 10 minutes during the first half hour, every 15 minutes in the next half hour, and hourly for the next six hours. Subjects also monitored their peak expiratory flow rate before and hourly after they left the laboratory until bedtime. A fall in $\mathrm{FEV}_{1}>15 \%$ within 24 hours after exposure was considered a positive test. ${ }^{11}$
Concentrations of welding fume during challenge tests were measured with cellulose ABC filters, $0.8 \mu \mathrm{m}$ in thickness and $37 \mathrm{~mm}$ in diameter, mounted on a cellulose support pad placed on monitor cassettes (Costar Co, MA, USA). The cassettes were placed close to the breathing zone of the subject, 10 to $15 \mathrm{~cm}$ from his mouth. Air was drawn through the filter at a rate of $3 \mathrm{l} / \mathrm{min}$ with a calibrated pump (Airchecker Sampler model 224PCXR3). Filters were weighed before and after the challenge test to measure the total amount of particles collected. Qualitative and quantitative analysis of the type of metals in the samples was performed with flame atomic absortion spectrometry by the Occupational Hygiene Laboratory of the Workers' Compensation Board of British Columbia.

\section{SPECIFIC CHALLENGE TEST WITH METAL SALT} SOLUTIONS

Solutions of $0.3,0.6,1.2,2.5$, and $5 \mathrm{mg} / \mathrm{ml}$ zinc chloride in saline were used for the specific challenge test. After baseline spirometry was carried out, the subject inhaled saline nebulised for two minutes with a Bennett twin nebuliser at tidal breathing. Spirometry was repeated at one and 10 minutes after nebulisation. The same procedure was repeated starting with the lowest concentration of metal solutions. The inhalation test was discontinued when the highest concentration was reached or the $\mathrm{FEV}_{1}$ had fallen by $20 \%$.

SKIN TEST WITH METAL SALT SOLUTIONS

Skin prick tests with solutions of nickel sulphate, chromium sulphate, and zinc chloride at $0.3,0.6,1.2,2.5$, and $5.0 \mathrm{mg} / \mathrm{ml}$ were carried out. Twenty healthy controls without a history of exposure were also tested with the metal solutions in a similar manner. Patches were also tested with the standard closed technique for potassium dichromate $0.5 \%$, nickel sulphate $0.5 \%$, and zinc chloride. ${ }^{12}$

\section{Results}

CHARACTERISTICS OF STUDY SUBJECTS

Table 1 shows the characteristics of the study subjects. Subjects 1,4 , and 5 had normal lung function. All except subject 4 had evidence of non-specific bronchial hyperresponsiveness. Subjects 1,3 , and 4 gave a history of cough, chest tightness, and dyspnoea on exposure to several types of welding fumes. Subjects 5 and 6 had respiratory symptoms only on exposure to fumes from galvanised metal whereas subject 2 had symptoms on exposure to stainless steel welding fumes. None of the subjects complained of symptoms on exposure to fumes from mild steel welding.

\section{WELDING CHALLENGE TEST}

Table 2 show the results of the welding challenge tests. Three subjects $(1,5$, and 6$)$ had positive immediate bronchial reactions. Subject 1 reacted to both mild steel and stainless steel welding, subject 6 to mild steel and galvanised welding, and subject 5 to only galvanised welding. The remaining subjects did not react 
Table 2 Results of welding challenge test

\begin{tabular}{|c|c|c|c|c|c|c|}
\hline \multirow[b]{2}{*}{ Subject } & \multicolumn{2}{|c|}{$\begin{array}{l}\text { Exposure } \\
\text { (min) }\end{array}$} & \multicolumn{2}{|c|}{$\begin{array}{l}\text { Welding fumes } \\
\left(\mathrm{mg} / \mathrm{m}^{3}\right)\end{array}$} & \multicolumn{2}{|c|}{$\%$ Fall in $F E V_{1}$} \\
\hline & $M S$ & $s S$ & $M S$ & $s S$ & $M S$ & $s S$ \\
\hline 1 & 60 & 60 & 3.37 & 7.75 & 23 & 18 \\
\hline 2 & 60 & 60 & 3.89 & 2.96 & 7 & 10 \\
\hline 3 & 60 & 60 & 2.24 & 5.19 & 3 & 9 \\
\hline \multirow[t]{2}{*}{4} & 60 & 60 & - & 7.80 & 3 & 6 \\
\hline & $M S$ & $G S$ & $M S$ & $G S$ & $M S$ & $G S$ \\
\hline 5 & 60 & 45 & 1.33 & 150.00 & 2 & 17 \\
\hline 6 & 60 & 15 & 12.60 & 43.90 & 16 & 20 \\
\hline
\end{tabular}

Threshold limit value for welding fume is $5 \mu \mathrm{g} / \mathrm{m}^{3}$. MS $=$ mild steel; SS=stainless steel; GS=galvanised steel.

to either mild steel or stainless steel welding. Late asthmatic reactions and systemic symptoms were not found.

CONCENTRATION OF WELDING FUMES

Table 2 shows the concentrations of welding fumes during challenge tests. Mild steel welding generated fume concentrations ranging from $1.3-12.6 \mathrm{mg} / \mathrm{m}^{3}$. Stainless steel welding generated higher fume concentrations than mild steel welding. Galvanised welding generated the highest concentration of fumes; subject 5 was exposed to a concentration of welding fumes of $150 \mathrm{mg} / \mathrm{m}^{3}$. Table 3 shows the results of qualitative and quantitative analysis of welding fumes that subjects 3,5 , and 6 were exposed to. Small amounts of chromium and nickel were found in stainless steel welding fumes and high concentrations of zinc were found in galvanised welding fumes.

INHALATION CHALLENGE TEST WITH METAL SALT SOLUTIONS

As welding fumes from galvanised metal contained a high level of zinc, inhalation challenge tests were carried out on subjects 5 and 6 with increasing concentrations of $\mathrm{ZnCl}_{2}$ salt solution. Both patients did not react to the highest concentration of this solution.

IMMUNOLOGICAL TESTS WITH METAL SALT SOLUTIONS

Subjects 5 and 6 had skin prick and patch tests with different metal salts. Both subjects and healthy controls showed negative skin test reactions to all metal salts. Patch tests with various metal salts on subjects 5 and 6 were also negative.

\section{Discussion}

Welders are at risk of developing occupational asthma because of exposure to both sensitising metals and irritant gases. The subjects in this study performed manual metal arc welding on mild steel, stainless steel, and galvanised metal.
The composition of particles in welding fumes is dependent on the material being welded and the electrodes used in the welding process. Welding on mild steel produces fumes containing aluminum, magnesium, fluoride, potassium, calcium, manganese, iron, titanium, and trace amounts of cobalt, zinc, and lead whereas welding on stainless steel produces all these elements and also chromium and nickel..$^{13}$ Of these metals, cobalt, zinc, chromium, and nickel have been shown to give rise to occupational asthma. ${ }^{14}$ The mechanism of induction of asthma by exposure to welding fumes containing nickel and chromium is not known. Specific IgE antibodies to nickel salt conjugated to human serum albumin have been reported in some patients with occupational asthma due to nickel exposure but not in others. ${ }^{15-19}$ Proliferation of lymphocytes of patients with occupational asthma due to nickel or chromium salts was found when stimulated with the metal salt conjugated with human serum albumin suggesting that a cell mediated hypersensitivity reaction may be the immunological mechanism involved. ${ }^{20}$

Malo and Cartier ${ }^{2}$ showed that exposure to fumes of galvanised metal gave rise to a late asthmatic reaction in two subjects working with solder. One of them also had fever and increased neutrophils. The fume was found to contain $22 \mathrm{mg} / \mathrm{m}^{3}$ of zinc. In another report, the same group of investigators showed positive immediate skin and bronchial reaction to zinc sulphate in a patient with occupational asthma due to exposure to galvanised metal fumes. ${ }^{3}$ Specific IgE antibodies to zinc were not found. The amount of zinc in the soldering fumes the patient was exposed to during the specific challenge test was very low $\left(0.015 \mathrm{mg} / \mathrm{m}^{3}\right)$ and the patient did not react to soldering on steel. Thus the bronchial reaction was specific and the authors concluded that zinc can cause occupational asthma. ${ }^{3}$ Weir et $a l^{4}$ reported two subjects with occupational asthma associated with the use of soft corrosive fluxes containing zinc chloride and ammonium. They challenged one of the subjects with zinc chloride solution but did not induce an asthmatic reaction.

In this study, three welders had bronchial reactions to welding challenge testing. One reacted to fumes from both mild and stainless steel welding; two reacted to fumes from galvanised metal welding, one of whom also reacted to fumes from mild steel welding. All three welders had respiratory symptoms and evidence of bronchial hyperresponsiveness to indicate that they had asthma.

Table 3 Analysis of welding fumes to which subjects 1, 3, 5, and 6 were exposed

\begin{tabular}{|c|c|c|c|c|c|c|c|c|c|}
\hline & \multirow[b]{2}{*}{$\begin{array}{l}T L V \\
\mathrm{mg} / \mathrm{m}^{3}\end{array}$} & \multicolumn{2}{|c|}{ Subject 1} & \multicolumn{2}{|c|}{ Subject 3} & \multicolumn{2}{|c|}{ Subject 5} & \multicolumn{2}{|c|}{ Subject 6} \\
\hline & & $\begin{array}{l}M S \\
m g / m^{3}\end{array}$ & $\begin{array}{l}S S \\
\mathrm{mg} / \mathrm{m}^{3}\end{array}$ & $\begin{array}{l}M S \\
m g / m^{3}\end{array}$ & $\begin{array}{l}S S \\
m g / m^{3}\end{array}$ & $\begin{array}{l}M S \\
m g / m^{3}\end{array}$ & $\begin{array}{l}\text { SS } \\
m g / m^{3}\end{array}$ & $\begin{array}{l}M S \\
m g / m^{3}\end{array}$ & $\begin{array}{l}S S \\
m g / m^{3}\end{array}$ \\
\hline Chronium & 1 & $<0.01$ & 0.23 & ND & 0.03 & ND & 0.03 & 0.005 & 0.01 \\
\hline Iron $\star$ & 5 & 0.27 & 0.18 & 0.46 & 0.07 & 0.19 & 15.4 & 4.56 & 5.85 \\
\hline Manganese & 5 & 0.10 & 0.25 & 0.04 & 0.02 & 0.04 & 3.2 & 0.3 & 1.08 \\
\hline Nickel & 0.1 & ND & 0.02 & ND & 0.01 & ND & ND & ND & ND \\
\hline Zinc & 5 & 0.01 & 0.02 & 0.01 & 0.005 & 0.01 & 79.5 & 0.025 & 10.5 \\
\hline
\end{tabular}

*TLV for iron oxide. $\mathrm{ND}=$ not detected; $\mathrm{TLV}=$ threshold limit value; $M S=$ mild steel; $S S=$ stainless steel. 
They developed immediate bronchoconstriction on exposure to high concentrations of welding fumes and none of them had a late reaction, suggesting that the reaction is a nonspecific one due to irritation rather than sensitisation. Immunological tests on the two subjects who developed bronchoconstriction to galvanised metal welding were also negative. The results of this study underscore the importance of monitoring levels of exposure in any occupational challenge tests to enable appropriate interpretation of the results.

\section{Conclusions}

We found that three of the six welders in this study with respiratory symptoms developed immediate bronchial reaction when exposed to welding fumes. The mechanism of bronchial reaction in these three welders is likely to be non-specific and due to irritation rather than due to specific sensitisation.

We thank Dr Susan Kennedy for her encouragement and assistance in this study.

1 Keskinen HA, Kalliomaki PL, Alanko K. Occupational asthma due to stainless steel welding fumes. Clin Allergy 1980;10:151-9

2 Malo JL, Cartier A. Occupational asthma due to fumes of galvanised metal. Chest 1987;92:375-6.

3 Malo JL, Cartier A, Dolovich J. Occupational asthma due to zinc. Eur Respir $\mathcal{F}$ 1993;6:447-50.

4 Weir D, Robertson A, Jones S, Burge P. Occupational asthma due to soft corrosive soldering fluxes containing zinc chloride and ammonium chloride. Thorax 1989;44: 220-3.
5 Broughton A, Thrasher JD, Gard Z. Immunological evaluation of four arc welders exposed to fumes from ignited polyurethane (isocyanate) foam: antibodies and immune profiles. $A m \mathcal{F}$ Ind Med 1988;13:463-72.

6 Vogelmeier C, Konig G, Bencze K, Fruhmann G. Pulmonary involvement in zinc fume fever. Chest 1987;92: 946-8.

7 Vandenplas O, Dargent F, Auverdin JJ, Boulanger J, Bossiroy JM, Roosels D, Vand Weyer R. Occupational asthma due to gas metal arc welding of mild steel. Thorax asthma due to gas

8 American Thoracic Society. Standardization of spirometry. 1987 Update. Am Rev Respir Dis 1987;136:1285-07.

9 Crapo RO, Morris AH, Gardner RM. Reference spirometric values using techniques and equipment that meet ATS recommendations. Am Rev Respir Dis 1981;123:659-64.

10 Cockcroft D, Killian D, Mellon J. Hargreave FE. Bronchial reactivity to inhaled histamine. A method and clinical survey. Clin Allergy 1977;7:235.

11 Hutchcroft B, Pepys J. State of the art - bronchoprovocation tests in the etiologic diagnosis of ashtma. Am Rev Respir Dis 1975;112:829-59.

12 Fisher AA. Contact dermatitis. 3rd ed. Philadelphia: Lea and Febiger, 1986

13 Stern R. A chemical, physical and biological assay of welding fumes. Copenhagen: The Danish Welding Institute, 1977: 16. (Publication 7705.)

14 Chan-Yeung $M$, Malo JL. Etiologic agents in occupational asthma. Eur Respir ₹ 1994;7:346-70.

15 Malo JL, Cartier A, Gagnon G, Evans S, Dolovich J. Isolated late asthmatic reaction due to nickel sulphate without antibodies to nickel. Clin Allergy 1985;15:95-100.

16 Block $\mathrm{G}$, Chan-Yeung $M$. Asthma induced by nickel. $¥ A M A$ 1982;247:1600-2.

17 Novey $\mathrm{H}$, Habib $M$, Wells I. Asthma and IgE antibodies induced by chromium and nickel salts. $\mathcal{f}$ Allergy Clin Immunol 1983;72:407-12.

18 Olaguibel J, Bascomba A. Occupational asthma induced by chromium salts. Allergol Immunopathol (Madr) 1989;17: 133-6.

19 Nieboer E, Evans SL, Dolovich J. Occupational asthma from nickel sensitivity: II. Factors influencing the interaction of Ni2+, HSA, and serum antibodies with nickel related specificity. $\mathrm{Br}$ F Ind Med 1984;41:56-63.

20 Bernstein IL, Brooks SM. Metals. In: Bernstein IL, Chan-Yeung M, Malo JL, Bernstein D, eds. Asthma in the workplace. New York: Marcel Dekker, 1993:481-502. 